\title{
Educação Especial, pandemia e o projeto educativo do capital: a produção de um consenso
}

\section{Resumo}

Este artigo tem por objetivo trazer alguns elementos para a discussão sobre como está sendo produzido o consenso a respeito das propostas educacionais para a Educação Especial durante a pandemia da COVID-19. Para tanto, analiso documentos nacionais e de organizações empresariais que trazem orientações para a educação brasileira nesse momento específico e realizo o balanço de produções acadêmicas sobre "Educação Especial / COVID-19", tendo em vista o alto número de publicações a esse respeito no último ano. Pode-se perceber que está em curso no Brasil o projeto de educação pública pautado pelo capital, o qual está sendo intensificado durante a pandemia. No caso da Educação Especial, a proposta do governo, dos grupos empresariais e de grande parte dos pesquisadores está coesa, seja no ensino remoto ou nas aulas presenciais, o foco está na necessária adaptação e treinamento do professor, na exaltação do uso das tecnologias e na flexibilização curricular para os estudantes dessa modalidade de ensino. A relação família-escola também é um fator de comum acordo, indicado como algo insuficiente antes da pandemia e que hoje ganha força, sendo visto como o resultado positivo da tragédia sanitária que o mundo está vivendo. Os consensos produzidos resultam, em suma, na implementação da privatização da escola pública, em suas diversas dimensões, escancarada na pandemia e potencializada também nas indicações para a Educação Especial na escola regular.

Palavras-chave: Educação Especial; COVID-19; organizações empresariais; políticas educacionais; relações público-privadas.

\section{Kamille Vaz}

Universidade Federal de Minas

Gerais - UFMG - Belo Horizonte/MG - Brasil kamillevaz@ufmg.br

\section{Para citar este artigo:}

VAZ, Kamille. Educação Especial, pandemia e o projeto educativo do capital: a produção de um consenso.

Revista Linhas. Florianópolis, v. 22, n. 49, p. 106-131, maio/ago. 2021. 


\title{
Special Education, pandemia and the capital educational project: the production of a consensus
}

\begin{abstract}
This article aims to bring some elements to the discussion about how consensus is being produced regarding educational proposals for Special Education during the COVID-19 pandemic. To this end, I analyze national documents and those of business organizations that provide guidance for Brazilian education at that specific moment and carry out the balance of academic productions on "Special Education / COVID-19", in view of the high number of publications on this subject in the last year. It can be seen that the public education project based on capital is underway in Brazil, which is being intensified during the pandemic. In the case of Special Education, the proposal of the government, business groups and most of the researchers is cohesive, whether in remote education or in face-to-face classes, the focus is on the necessary adaptation and training of the teacher, in the exaltation of the use of technologies and in curricular flexibility for students in this teaching modality. The family-school relationship is also a factor of common agreement, indicated as something insufficient before the pandemic and that today is gaining strength, being seen as the positive result of the health tragedy that the world is experiencing. The consensus produced results, in short, in the implementation of the privatization of the public school, in its various dimensions, wide open in the pandemic and also punctuated in the indications for Special Education in the regular school.
\end{abstract}

Keywords: Special Education; COVID-19; company organizations; educational policies; public-private relations. 
Neste artigo, desenvolvi análises preliminares sobre a Educação Especial nas escolas públicas brasileiras em tempos de ofensiva do Capital e de crise sanitária, agravada pela COVID-19. Para tanto, analisei documentos nacionais e de organizações empresariais ${ }^{1}$, assim como da produção acadêmica divulgada pelo campo específico sobre a Educação Especial. A intenção foi compreender como está sendo formado o consenso a respeito da educação dos estudantes da Educação Especial neste momento histórico e quais as relações com o projeto de escola pública e de Educação Especial pautados pelo capital para o Brasil.

Os documentos analisados foram: Parecer do Conselho Nacional de Educação (CNE)/Conselho Pleno (CP) n. 5, de 28 de abril de 2020 (BRASIL, 2020a); Parecer CNE/CP n. 11, de 7 de julho de 2020 (BRASIL, 2020b); Nota Técnica: o retorno às aulas presenciais no contexto da pandemia da COVID-19 (TPE, 2020); Protocolos sobre Educação Inclusiva durante a pandemia da COVID-19: um sobrevoo por 23 países e organismos internacionais (INSTITUTO RODRIGO MENDES, 2020); Retratos da educação no contexto da pandemia do Coronavírus: um olhar sobre múltiplas desigualdades (CONHECIMENTO SOCIAL, 2020). A escolha desses documentos está embasada na importância que esses grupos representam na elaboração de políticas educacionais, e aqui destaco alguns deles.

Em meio à crise econômica, política, sanitária e ambiental que o mundo está vivendo no século XXI, as Organização Multilaterais (OM) continuam encaminhando o projeto educacional para os países em desenvolvimento, como é o caso da Organização das Nações Unidas para a Educação, a Ciência e a Cultura (UNESCO), com a Coalizão Global de Educação, que se constitui em uma plataforma de colaboração e intercâmbio para proteger o "direito à educação" durante esse período de interrupção das aulas presenciais. Com a estratégia “\#AprendizagemNuncaPara”, essa coalizão reúne membros da Organização das Nações Unidas (ONU), sociedade civil e setor privado².

\footnotetext{
${ }^{1}$ Utilizo essa denominação para expressar o que Martins (2009) chama de "Direita para o social” compondo um projeto neoliberal de terceira via. Dentro dessa nomenclatura encontram-se instituições, associações, fundações, entre outras. Para este artigo, destaco os grupos Todos Pela Educação, Instituto Rodrigo Mendes e a empresa de consultoria Conhecimento Social.

2 Maiores informações podem no sítio: <https://pt.unesco.org/covid19/educationresponse/globalcoalition>.
} 
As OM são uma importante ferramenta de implementação e manutenção das relações sociais vigentes, inclusive quando se trata do projeto educacional dos países em desenvolvimento, contribuindo com a criação de redes locais como "parte da estratégia de construir sentimento de pertença nos 'atores locais', para que se engajem em ações pela Educação" (SHIROMA, 2012, p. 90). Importante destacar que todos os documentos das organizações empresariais analisados para este trabalho, utilizam as orientações produzidas pela UNESCO e pela coalização para pautar suas indicações para a educação brasileira.

O projeto educacional para o Brasil está em curso, independente de estarmos em um momento crítico de saúde pública. A pandemia causada pela COVID-19, está servindo como uma estratégia para acelerar e fortalecer a implementação do projeto privatista para a educação brasileira. Souza e Evangelista destacam que

As sugestões oferecidas pelas Organizações Multilaterais estão, óbvio, em andamento. No Rio de Janeiro, a parceria com o Google for education é do ano passado [2019] e foi potencializada nesse momento. Ao menos seis estados brasileiros fecharam parceria com o Google: Rio Grande do Norte, Ceará, Rio de Janeiro, Santa Catarina; Paraná e Rio Grande do Sul (UNESCO, 2020). No Paraná, os professores da Rede Estadual de Educação gravarão as aulas e elas, após serem transmitidas em canais de televisão pagos pelo governo, serão armazenadas no Google for education. (SOUZA; EVANGELISTA, 2020)

Ao considerar tais indicações, pode-se compreender que o projeto educacional para o Brasil, pautado pelo capital, já estava sendo implementado anteriormente à pandemia. Conforme aponta Freitas,

[...] a educação está sendo sequestrada pelo empresariado para atender a seus objetivos de disputa ideológica. A educação, vista como um "serviço" que se adquire, e não mais como um direito, deve ser afastada do Estado, o que justifica a sua privatização. Do ponto de vista ideológico, a privatização também propicia um maior controle político do aparato escolar, agora visto como "empresa", aliado à padronização promovida pelas bases nacionais comuns curriculares e pela ação do movimento "escola sem partido", esse último, um braço político da "nova" direita na escola. (FREITAS, 2018, p. 29) 
As recomendações para a educação brasileira durante a pandemia causada pela COVID-19, seja no ensino remoto, ou no retorno às aulas presenciais são, de certa forma, uma vitrine do projeto de escola pública que está em curso para os países periféricos na sociedade capitalista. Os documentos aqui apresentados indicam essa convergência de pensamentos que expressam o projeto de escola pública para o capital, inclusive quando tratamos da Educação Especial na escola regular, como indicarei a seguir. Dessa forma, a título de organização de exposição, serão apresentados, em um primeiro momento, aspectos gerais sobre os documentos analisados; posteriormente, elementos descritivos e analíticos iniciais sobre o balanço de produções acadêmicas, para, em posse dessas discussões iniciais, tentar estabelecer algumas relações entre o discurso político, as pesquisas acadêmicas e o projeto educacional em pauta.

\section{O dito pelo não dito: a aposta no discurso humanitário}

Em fevereiro de 2020, o mundo foi assolado pela notícia da pandemia causada pela COVID-19. Algumas das medidas adotadas para a contenção do vírus foram o isolamento social e, com isso, o fechamento das escolas. No Brasil, em abril de 2020, o Conselho Nacional de Educação (CNE) / Conselho Pleno (CP) divulgou o Parecer n. 05 (BRASIL, 2020a), aprovado em 29 de maio de 2020. Neste, os representantes do Conselho, apontam a necessidade de "reorganização do calendário escolar e da possibilidade de cômputo de atividades não presenciais para fins de cumprimento da carga horária mínima anual, em razão da Pandemia da COVID-19" (BRASIL, 2020a, p. 1).

A preocupação geral foi com a impossibilidade de repor os dias letivos, caso as aulas não retornassem. Tal destaque foi ganhando força entre as entidades e as redes de ensino, o que gerou, em nível nacional, uma corrida para o retorno de aulas não presenciais. A depender das redes, diversas formas de execução desse modelo de ensino foram sugeridas - aulas on-line em plataformas privadas (Microsoft Teams, Google For Education, entre outras); aulas gravadas e disponibilizadas em plataformas próprias das redes de ensino ou no Youtube; aulas via WhatsApp, por telefone, rádio e televisão; entrega de material impresso para os estudantes. 
Com relação à Educação Especial, está destacado no referido Parecer que as propostas educacionais para o momento de pandemia devem ser asseguradas também para os estudantes dessa modalidade de ensino. Para isso, enfatizam que os professores do Atendimento Educacional Especializado (AEE)

[...] atuarão com os professores regentes em rede, articulados com a equipe escolar, desempenhando suas funções na adequação de materiais, provimento de orientações específicas às famílias e apoios necessários. Eles também deverão dar suporte às escolas na elaboração de planos de estudos individualizados, seguindo a individualidade dos alunos, a serem disponibilizados e articulados com as famílias. (BRASIL, 2020a, p. 15)

Interessante destacar deste trecho a função do professor do Atendimento Educacional Especializado (AEE) como "adequador" de materiais, o que já vem sendo expresso na documentação representativa da política de Educação Especial desde 2008, e o foco na aprendizagem individualizada, como ficará mais evidente com os demais documentos.

Posteriormente ao Parecer CNE/CP n. 5 (BRASIL, 2020a), O CNE/CP divulgou o Parecer n. 11 (BRASIL, 2020b), o qual apresenta "Orientações Educacionais para a Realização de Aulas e Atividades Pedagógicas Presenciais e Não Presenciais no contexto da Pandemia" (BRASIL, 2020b, p. 1). Instaurada a necessidade de retorno às aulas, mesmo que de forma on-line, o CNE apresentou as orientações para efetivar essa proposta, já vislumbrando o retorno presencial às escolas, mesmo que com o aumento do contágio pelo vírus.

A respeito da Educação Especial, as indicações são as mesmas pautadas para a educação básica, entretanto, ressaltam que o retorno presencial desses sujeitos é mais complicado e deve estar atrelado à avaliação médica e da família. O texto é claro ao apresentar todas as condições que impedem a participação dos estudantes da Educação Especial no retorno presencial, e que por suas condições individuais e específicas, devem ser privados de interações presenciais (BRASIL, 2020b). Cabem aqui algumas indagações: Se o contágio do vírus continua sendo uma preocupação que leva o CNE a privar os estudantes da Educação Especial de retornarem às aulas presenciais, essa preocupação 
não deveria se estender aos demais estudantes? Qual a avaliação de risco entre os estudantes? É certo que os demais estudantes não sofrerão com a doença causada pela COVID-19 ou com os ditos protocolos sanitários nas escolas? Qual a pressão que está sendo exercida para que as escolas retornem presencialmente? Os documentos feitos pelas organizações empresariais selecionados para este estudo apresentam alguns indícios.

Na mesma direção do CNE, em maio de 2020 foi publicada a Nota Técnica: O retorno às aulas presenciais no contexto da pandemia da COVID-19, produzida pelo grupo Todos pela Educação, com auxílio do Instituto Sonho Grande e do Instituto Ayrton Senna ${ }^{3}$. A nota apresenta a pesquisa realizada sobre experiências de outros países que se assemelham a que estamos vivendo atualmente no mundo. Segundo o grupo, olhar para o que já foi realizado é a peça-chave para o suposto sucesso.

O objetivo é planejar o retorno presencial para as escolas. Dentre os pontos que sustentam esse documento, destaca-se o fato de afirmarem que o retorno exigirá um plano de ações em diversas frentes, como: planejar o retorno gradual; reorganizar o calendário escolar; realizar uma avaliação diagnóstica; comunicação frequente com as famílias; articulação entre diversos órgãos; contextualizar as medidas no nível da escola.

O documento traz experiências de outros países que já estavam retornando às aulas presenciais, garantindo os protocolos sanitários como o distanciamento social, escalonamento dos alunos, aulas em locais abertos e ventilados. Indica a ampliação da jornada diária nas escolas, reposição de aulas aos sábados e em turno alternativos, prorrogação de férias e recessos para garantir a carga horária obrigatória e revisão dos objetivos de aprendizagem com possibilidade de compensação no ano seguinte.

Um dos pontos que aparecem nos documentos analisados é a necessidade de realizar avaliação diagnóstica dos estudantes e propor reforços e recuperação. Espanta essa proposição, pois parece que essas ações são novidade no cotidiano das escolas, como se todos esses protocolos já não fizessem parte do planejamento escolar. Trazem

\footnotetext{
3 Instituto Sonho Grande e Instituto Ayrton Senna são Organizações sem fins lucrativos que atuam na elaboração de propostas educacionais junto ao movimento dos empresários, visando protagonizar as políticas educacionais brasileiras. Estão entre os parceiros, o Instituto Natura; o Instituto de Corresponsabilidade pela Educação; o Itaú Social; o Grupo de Líderes Empresariais (LIDE)/Educação, dentre muitos outros.
} 
como inovação algo que já está previsto na legislação da área e que deveria ser rotina nas escolas. Observa-se nesse ponto, que as abordagens apresentadas pelo Todos pela Educação, estão em consonância com os direcionamentos do CNE.

Todos pela Educação é uma organização da sociedade civil que se diz suprapartidária. Visa, segundo eles, contribuir com a educação básica no Brasil, auxiliando e orientando os gestores públicos sobre o tema. Shiroma afirma que

O compromisso Todos pela Educação visa mobilizar a iniciativa privada e as organizações sociais para atuar de forma convergente, complementar e sinérgica com o Estado na definição das políticas públicas. $O$ ponto central de sua estratégia é a corresponsabilidade e a busca de eficiência, eficácia e efetividade. Seu enfoque é primordialmente voltado à melhoria da qualidade do ensino traduzida em resultados mensuráveis obtidos por meio de avaliações externas. (SHIROMA, 2012, p. 106)

O documento aqui apresentado, vem na esteira das produções já elaboradas pelo Todos Pela Educação. Importante ressaltar que esse documento contou com o apoio técnico de cinco especialistas ${ }^{4}$ em educação com experiência em gestão pública educacional, dos quais, a maioria participou na gestão de governos do Partido da Social Democracia Brasileira (PSDB). Ou seja, o discurso de estar acima das discussões partidárias não se corporifica ao nos depararmos com os intelectuais orgânicos ${ }^{5}$ da burguesia que produzem e divulgam essa ideia e que compõem a organização Todos Pela Educação.

\footnotetext{
${ }^{4}$ São eles: Alexandre Schneider, que foi secretário de educação do município de São Paulo nas gestões de Gilberto Kassab (DEM) e João Dória (PSDB); Alexsandro Santos, foi secretário adjunto de educação em Franco da Rocha na gestão de Kiko Celeguim (PT); Cláudia Costin, foi ministra de Administração e Reforma do Estado durante a presidência de Fernando Henrique Cardoso (PSDB), Secretária de Cultura do estado de São Paulo durante a primeira gestão de Geraldo Alckmin (PSDB) e Secretária de Educação no município do Rio de Janeiro no governo de Eduardo Paes (PMDB); Raquel Teixeira, foi Secretária de Ciência e Tecnologia do estado de Goiás durante o governo de Marconi Perillo (PSDB) e, posteriormente, foi Secretária de Cidadania no governo de Alcides Rodrigues (PP). Foi também deputada federal pelo estado de Goiás por dois mandatos pelo PSDB; Washington Bonfim foi Secretário de Educação e de Planejamento do município de Teresina (PI) no governo de Silvio Mendes (PSDB) e Firmino Filho (PSDB), respectivamente.

5 Intelectual orgânico, para Gramsci, é o sujeito individual ou coletivo que exerce função ideológica para construir e manter a hegemonia de determinado grupo. Como elucida Gramsci (2000, p. 15) "Todo grupo social, nascendo no terreno originário de uma função essencial no mundo da produção econômica, cria para si, ao mesmo tempo, organicamente, uma ou mais camadas de intelectuais que lhe dão homogeneidade e consciência da própria função, não apenas no campo econômico, mas também no social e político".
} 
Outro documento importante sobre o assunto publicado em parceria com o Todos Pela Educação, intitulado Protocolos sobre educação inclusiva durante a pandemia da COVID-19: um sobrevoo por 23 países e organismos internacionais, foi produzido pelo Instituto Rodrigo Mendes ${ }^{6}$ com apoio da DIVERSA, Fundação Grupo Volkswagem; Fundação Lemann; Instituto Credit Suisse Hedging-Griffo; Instituto Unibanco; Instituto Península; Itaú Social; e UNICEF. O documento visa socializar as práticas e diretrizes adotadas por 23 países com relação ao retorno presencial no período de pandemia causado pela COVID-19. O objetivo é orientar os gestores públicos, escolas, professores, famílias e estudantes público da Educação Especial para as possibilidades concretas de retorno das aulas presenciais, assim como foi feito nesses países analisados, com os protocolos de segurança sanitária já adotados durante a pandemia.

Ou seja, as diretrizes apontadas pela UNESCO estão sendo encaminhadas nos documentos oficiais e das organizações empresariais, produzindo o discurso que transparece uma suposta hegemonia sobre o retorno às aulas presenciais. O CNE, em julho de 2020, publica as orientações para as aulas presenciais e não presenciais (BRASIL, 2020b); no mesmo ano, as organizações empresariais publicam diversos documentos orientando a sociedade civil e contribuindo para a produção de consenso em torno das propostas para a educação brasileira. No caso da Educação Especial, o Instituto Rodrigo Mendes apresenta um protagonismo sobre as propostas e encaminhamentos para essa modalidade de ensino nas escolas regulares convergindo com as indicações das OM.

O destaque do referido documento está na necessidade dos estudantes da Educação Especial estarem incluídos nesse retorno, garantindo o suposto direito à educação que se traduz no discurso desse instituto com o slogan de inclusão escolar. Para isso, aborda questões recomendadas por Organizações Multilaterais, como a UNESCO, ONU e UNICEF, relacionadas à garantia do que chamam de retorno de qualidade e de combate das desigualdades de oportunidades. Para a Educação Especial nas escolas básicas, o documento retoma a necessidade de: garantir a individualidade, o material didático adaptado, professores de apoio, atenção aos familiares, avaliação diagnóstica e

\footnotetext{
6 O Instituto Rodrigo Mendes é uma Organização sem fins lucrativos que desenvolve programas de educação inclusiva desde 1994. O Instituto apresenta cursos de formação continuada de professores desenvolvidos para as redes de ensino interessadas. Em parceria com o Ministério da Educação, desenvolve o projeto DIVERSA que tem como objetivo realizar orientações às redes de ensino sobre a proposta de educação inclusiva para os estudantes da Educação Especial, com base na socialização de práticas exitosas.
} 
processual e treinamento de professores. Esse último aparece muitas vezes durante o documento, ressaltando que os professores devem ser treinados para atuar nessa retomada das aulas com o uso, em destaque, das tecnologias. Ao professor, é requerido no documento, que esteja disponível 24 horas por dia, por rádio, por WhatsApp, telefone e pela televisão, para garantir que o estudante não se sinta isolado da escola.

O documento Retratos da Educação no contexto da pandemia do Coronavírus: um olhar sobre múltiplas desigualdades (2020), publicado pela empresa de consultoria educacional Conhecimento Social, teve como parceiros a Fundação Carlos Chagas, Fundação Lemann, Fundação Roberto Marinho, Instituto Interdisciplinaridade e Evidências no Debate Educacional (IEDE), Instituto Península e Itaú Social7. O objetivo foi demostrar, com base em pesquisas realizadas, como a educação brasileira é desigual e o quanto, na pandemia, isso se intensificou. Dentre as limitações encontradas, destacam a falta de formação adequada dos professores para este momento que estamos vivendo.

[...] diante da dificuldade apontada por estudantes de todos os perfis para organizar-se para os estudos - tornou-se mais evidente a importância assegurar formação e condições de trabalho que consolidem o papel do professor como mediador do aprendizado, formando sujeitos autônomos, capazes de gerir processos de aprendizagem e rotinas de estudo na busca de conhecimento e desenvolvimento pessoal. (CONHECIMENTO SOCIAL, 2020, p. 48)

A compreensão geral está pautada na formação do sujeito autônomo; inclusive nos estudos, o professor é um tipo de mediador ou facilitador do processo. Destaca-se aqui o projeto de formação de professores centrada na prática, o qual desde o início do século vem sofrendo com o processo de desintelectualização (MICHELS; SHIROMA; EVANGELISTA, 2011). Segundo as reflexões apresentadas por Martins e Pina (2017) sobre a relação público-privada na educação e as ações desses grupos empresariais sobre a escola pública,

O objetivo é reduzir o trabalho do professor: de atividade de transmissão das formas mais desenvolvidas do conhecimento científico, filosófico e artístico a treinamento voltado à aquisição de "competências" consideradas úteis à reprodução das relações sociais de dominação contemporâneas. (MARTINS; PINA, 2017, p. 124)

\footnotetext{
7 Para compreender melhor a ação dessas instituições na educação brasileira, ler: FREITAS, L. C. de. A Reforma Empresarial da Educação: nova direita, velhas ideias. São Paulo: Expressão Popular, 2018.
} 
A intensificação do trabalho docente é expressa nos documentos analisados, mas são camufladas pelo discurso dos cuidados emocionais, da suposta preocupação de que todos devem estar passando por momentos difíceis. Entretanto, no momento em que é expressa a necessidade de retorno presencial às escolas, o risco à saúde física dos professores não é pautado; a sobrecarga de trabalho misturada entre ensino on-line e presencial também não é argumentada. As propostas não são diferentes do que já é pensado para a educação dos sujeitos da Educação Especial; a diferença está na utilização desse discurso como uma novidade para garantir o sentimento de algo que nunca foi garantido de fato. Estamos presenciando mais uma das armadilhas discursivas das políticas educacionais.

Todos os documentos selecionados, de uma forma ou de outra, indicam que sairemos com questões positivas dessa experiência que estamos vivendo na educação brasileira, reforçando a perspectiva empresarial de ver oportunidades em meio às crises. O documento Retratos da Educação no contexto da pandemia do Coronavírus cita que um dos legados mais efetivos que este momento nos deixará será a possibilidade de aprimorar as relações entre instâncias da gestão pública e da sociedade civil (CONHECIMENTO SOCIAL, 2020), ou seja, já está em curso o projeto de privatização da educação brasileira, o qual vem ganhando força com as políticas neoliberais, e que está sendo escancarado com a pandemia.

\section{De mãos dadas com as orientações nacionais: a produção acadêmica sobre Educação Especial e covid-19}

Optei por realizar o balanço de produções acadêmicas sobre Educação Especial nesse momento histórico específico por dois motivos: o primeiro se concentra no fato de que, ao longo do ano de 2020, muitos artigos foram produzidos com o objetivo de desenvolverem análises sobre como os estudantes da Educação Especial estão sendo incluídos no ensino pós-fechamento das escolas, ou seja, no ensino remoto. A primeira percepção era de que os pesquisadores do campo específico da Educação Especial estavam, em sua maioria, se dedicando a compreender e indicar possibilidades nesse período atípico. Dessa forma, ao tentar compreender como as proposições políticas estão encaminhando a Educação Especial neste momento, consideramos crucial verificar qual o 
consenso que está sendo produzido sobre Educação Especial na pandemia. O segundo motivo, na esteira do primeiro, está na compreensão de que ao pesquisar um tema, investigar o que já foi escrito sobre ele, as polêmicas, os conflitos, os referenciais utilizados são uma escolha metodológica interessante para compreender e estabelecer um diálogo fecundo sobre o mesmo (EVANGELISTA; SHIROMA, 2019). A intenção com esse balanço de produções acadêmicas é compreender, mesmo que de forma indicativa, quais as relações entre as orientações dos documentos produzidos por órgãos oficiais e pelas organizações empresariais e a produção acadêmica no campo específico, percorrendo a formação de consensos a respeito do projeto de escola pública para os estudantes da Educação Especial.

Na elaboração desse balanço de produções acadêmicas ${ }^{8}$, foram selecionadas 38 produções que estavam direcionadas ao foco do estudo, sendo 24 artigos ${ }^{9}$ científicos e 14 trabalhos em eventos acadêmicos ${ }^{10}$. Pode-se perceber que, ao analisar os trabalhos selecionados, a temática central estava relacionada à Educação Especial/COVID-19, trabalho docente e práticas pedagógicas. $\mathrm{Na}$ análise dos documentos selecionados para esta pesquisa, evidenciamos que as indicações de protocolos e orientações, todas, estão entrelaçadas com a prática pedagógica e o trabalho docente. Assim, optou-se por trazer os destaques dos trabalhos que compõem esse balanço de produções acadêmicas juntamente com as indicações dos documentos analisados, tentando captar a relação

\footnotetext{
8 A busca pelas produções acadêmicas foi no portal "Google acadêmico" com o descritor "COVID-19" "Educação Especial", juntos e com aspas em cada um. Na primeira triagem, foram encontrados 979 trabalhos, entretanto a grande maioria não se dedicava à análise da educação especial, mas a respeito da educação geral, educação infantil, ensino a distância, formação de professores, ensino e letramento, ensino superior, e ainda, estudos sobre matérias específicas, como: ciências, português etc. Assim, foram descartados. Fizemos a seleção dos trabalhos considerando os títulos, palavras-chave e resumos.

9 Dos 24 artigos científicos selecionados, cinco foram publicados, até o momento, em 2021, e o restante foi publicado no ano de 2020. Pode-se perceber que boa parte desses artigos são frutos de chamadas para dossiês com a temática específica COVID-19 e educação, o que indica o número expressivo de produções em 2020. Dos artigos selecionados, percebemos que versam sobre temas que aglutinam análises entre Educação Especial/COVID-19 e trabalho docente e/ou práticas pedagógicas relativas a esse momento específico.

10 Com relação aos trabalhos acadêmicos apresentados em eventos científicos, 10 dos 14 trabalhos selecionados foram apresentados no VI Seminário Nacional de Educação Especial / XVII Seminário Capixaba de Educação Inclusiva que ocorreu entre os dias 26 e 30 de outubro de 2020 , totalmente on-line. $\mathrm{Na}$ primeira análise sobre os trabalhos, percebe-se que eles se dividiam entre Educação Especial/COVID-19 e trabalho docente ou práticas pedagógicas para esse momento específico; esse último em maior número, assim como nos artigos científicos.
} 
entre a produção científica, os documentos orientadores e a produção de consenso em torno da educação, mais especificamente, da Educação Especial.

\section{Defesa da inclusão: adaptações da prática pedagógica em tempos de pandemia}

De início tivemos a intenção de selecionar os trabalhos em eixos de análises, considerando o enfoque dado nas pesquisas, entretanto, apesar de algumas pesquisas indicarem suas análises sobre o trabalho docente neste período, essas reflexões estavam pautadas na modificação das práticas pedagógicas para atuar no ensino remoto. Todos os trabalhos selecionados, de uma forma ou de outra, se dedicaram a compreender e a mostrar possibilidades de adaptação da ação docente para garantir a inclusão dos estudantes da Educação Especial nesse modelo de ensino remoto. Contudo, dentro desse grande eixo - prática pedagógica -, observamos a presença de três assuntos recorrentes: a importância da relação família-escola; o uso de tecnologias; e a flexibilização curricular.

Ao ler os trabalhos, fica evidente o olhar sobre o professor em seu aspecto prático. A pergunta que embasou boa parte das pesquisas foi: Como os professores que atuam com a Educação Especial nas escolas básicas estão organizando o seu trabalho? Ao que tudo indica, a questão sobre analisar o momento presente está ancorada nas atividades desenvolvidas no ensino remoto, muitas pautadas na individualização do currículo e no uso de tecnologias. Grande parte dos trabalhos focaram em analisar redes de ensino específicas e trouxeram a descrição da documentação oficial que regulamenta o ensino remoto. Destaca-se o elevado número de trabalhos que se constituíram em relatórios de pesquisas desenvolvidas durante a pandemia, pesquisas de opinião, em sua maioria, realizadas em forma de questionários on-line, pesquisas exploratórias e estudos de caso. Aqui, avultaremos alguns desses trabalhos publicados e lançaremos mão das análises feitas nos documentos selecionados, tentando verificar se há convergências entre as políticas educacionais, os documentos produzidos pelas organizações empresariais e a produção acadêmica.

A pesquisa desenvolvida sobre o município de Fortaleza, por Gomes et al. (2021), indica a importância da relação família-escola para que a proposta do ensino remoto 
tenha êxito; além disso, destaca o uso do WhatsApp para desenvolver as atividades e manter o contato constante, como descrevem:

Observa-se que a maioria desses professores seguem as indicações do documento orientador da SME para esse período de distanciamento social, buscando utilizar o tempo de home office para dar suporte aos mais professores na flexibilização de atividades, assim como na orientação às famílias, a fim de utilizar esse espaço para possibilitar o diálogo permanente entre família e escola. (GOMES et al., 2021, p. 146)

A respeito da relação família-escola, encontramos muitas pesquisas que enfatizavam esse tema, assim como está sendo difundido pelos documentos das organizações empresariais, veiculados pelo Todos pela Educação (TPE) no ano de 2020. No documento $O$ retorno às aulas presenciais no contexto da pandemia da COVID-19 (TPE, 2020), o grupo destaca que podemos sair com experiências positivas desse momento de isolamento social e, uma delas, é a relação família-escola, tendo em vista que, segundo eles, a relação que existia era insuficiente e a pandemia acabou proporcionando mais oportunidades de desenvolver esse vínculo. “Assim, a partir de uma aproximação 'forçada', é que surge a oportunidade de dar início a uma cultura de diálogo e parceria contínua entre as famílias e as escolas" (TPE, 2020b, p. 23). Na mesma linha de raciocínio, o Instituto Rodrigo Mendes, no documento Protocolos sobre educação inclusiva durante a pandemia da COVID-19, exalta que, a experiência em outros países “[...] apontou para o fato de que o diálogo entre escolas, estudantes e famílias ajuda a reduzir a ansiedade e também contribui para pensar previamente sobre possíveis situações específicas e necessidades que não haviam sido consideradas" (INSTITUTO RODRIGO MENDES, 2020, p. 31).

Nesse sentido, um aspecto importante a ser destacado é a relação entre a dita boa prática do professor e a comunicação com a família. A conclusão que se chega com os documentos e a produção acadêmica é que sem essa relação família-escola, nesse tempo de pandemia, não haverá êxito na aprendizagem. Conforme abordam Bezerra, Arruda e Silva, 
Percebe-se, que a prática docente do processo de aprendizagem em tempo de pandemia no contexto social do AEE, é discutida acerca da necessidade de um bom relacionamento entre família e a escola a fim de contribuir com a aprendizagem afetiva dos discentes com deficiência da educação infantil ao ensino fundamental I e II. (BEZERRA; ARRUDA; SILVA, 2020, p. 7)

A relação família-escola trazida pela maioria da produção acadêmica selecionada, apresenta uma ligação direta com o desempenho nas atividades desenvolvidas no ensino remoto. Na documentação analisada, essa relação está pautada na descentralização do trabalho do professor; de uma forma velada, indicam a importância dessa relação para a construção do vínculo emocional necessário ao bom desempenho do estudante.

Na esteira da exaltação da relação família-escola está a necessidade de manter e aprofundar as relações entre poder público e sociedade.

O período de interrupção das aulas presenciais tem nos deixado uma grande lição: não podemos esperar avançar na redução das desigualdades educacionais - intensificadas neste período - sem contar com a articulação e estratégias sistêmicas de envolvimento entre a escola e a família e, do mesmo modo, sem a atuação em rede e conjunta entre o poder público e a sociedade. (CONHECIMENTO SOCIAL, 2020, p. 56)

Essa estreita relação, entre o público e o privado na educação é pauta recorrente desde as reformas da década de 1990. Martins e Pina (2017, p. 123) alertam que "Para além do interesse de dirigir o processo de privatização da educação pública brasileira, as entidades empresariais têm recorrido a noção de 'parceria' como estratégia para promover maior controle do trabalho educativo desenvolvido nas escolas públicas".

Nesse momento específico, com a pandemia, podemos afirmar que as organizações empresariais, caracterizadas como aparelhos privados de hegemonia da burguesia, estão em pleno movimento de fortalecimento. Basta ver os institutos e agências que compõem os documentos analisados, os quais se repetem entre si, traçando metas para a educação brasileira e construindo um corpus documental, publicizado por instituições diferentes, mas que são planejados pelos mesmos grupos sociais representados pelas mesmas pessoas, inclusive compondo o Conselho Nacional de Educação. O CNE aponta, nas recomendações gerais para os sistemas de ensino, o 
Estabelecimento de redes colaborativas entre níveis educacionais e entidades públicas e particulares: com o objetivo de desenvolver estratégias curriculares comuns, compartilhamento de infraestrutura, estratégias avaliativas, organização de processos integrados de capacitação e docente e ordenamento de ações e rotinas destinadas ao processo atual e à perspectiva de retorno às atividades pedagógicas ou aulas presenciais. (BRASIL, 2020b, p. 19)

As ações pautadas por essas instituições da sociedade civil, como podemos perceber, estão em consonância com as políticas educacionais pautadas para a educação brasileira, e nela, a educação dos sujeitos público-alvo da Educação Especial. O que é enunciado em todos os documentos analisados e nas produções acadêmicas selecionadas é a importância de se repensar a prática, ou melhor, os professores precisam se adequar a esse novo momento, seja pela disponibilidade 24 horas por dia, como afirmado anteriormente, assim como no uso das tecnologias para garantir a inclusão escolar desses estudantes, mesmo que à distância, por aulas gravadas ou ao vivo.

Para garantir que os estudantes da Educação Especial sejam contemplados pelo ensino remoto, o discurso é pautado na flexibilização curricular. Uma recente pesquisa, publicada em parceria com Fundação Carlos Chagas, Universidade Federal do ABC, Universidade Federal do Espírito Santo e Universidade de São Paulo - Inclusão escolar em tempos de pandemia -, teve o objetivo de verificar os desafios enfrentados pelas professoras e professores da educação básica que atuavam com estudantes da Educação Especial nesse momento de ensino remoto, apontou que a maioria dos professores optaram por adaptar o currículo para esses sujeitos e elaboraram um novo Plano de Desenvolvimento Individualizado (PDI), ou seja, modificaram os objetivos, desenvolvimento e avaliação. A pesquisa destaca o esforço dos professores em produzirem atividades individualizadas, considerando a especificidade de cada estudante (FUNDAÇÃO CARLOS CHAGAS, 2021).

Em seu artigo, Magalhães endossa essa perspectiva ao afirmar que

Atualmente, professores e estudantes de todo o país vivem o desafio de práticas pedagógicas desconhecidas e precisam se adequar a um novo modo de ensino que não contempla as condições de aprendizagens específicas de muitos estudantes. Em razão disso, possibilitar materiais e recursos diversificados, aliados a propostas curriculares mais flexíveis, 
pode nos ajudar a pensar recursos pedagógicos menos engessadas não só para os estudantes com deficiência, mas para todos os alunos envolvidos neste processo.

Nesta direção, os conceitos de diferenciação curricular e DUA apresentados neste artigo, em muito podem contribuir para que se pensem novas práticas, não excludentes, não só para os estudantes com deficiência, mas para todos que se encontram neste momento, deslocados dos processos de ensino. (MAGALHÃES, 2020, p. 218)

O discurso produzido no documento Protocolos sobre Educação Inclusiva durante a pandemia da COVID-19 dialoga o tempo todo com as orientações produzidas pela UNESCO, especialmente no documento COVID-19: resposta educacional (UNESCO, 2020), das quais destaca a necessidade de "escolher os principais objetivos de aprendizagem para o ano letivo e ajustar o currículo, tais como aprendizagem baseada em projetos" (INSTITUTO RODRIGO MENDES, 2020, p. 44).

Apesar de todo esse discurso, que está sendo produzido nesse período de pandemia, se colocar como inovador, a discussão sobre adaptação ou flexibilização curricular na Educação Especial é antiga. Garcia e Michels (2018, p. 61) afirmam que "Se nas décadas de 1970 e 1980 a proposição era de ‘currículo individualizado' com ênfase nos diagnósticos, na década de 1990 temos uma transição desse pensamento para as 'diferenças individuais', e nos anos 2000 a proposição é alterada para a 'individualização do currículo'."

As indicações para tornar o ensino remoto viável e preparar para a volta às aulas presenciais não se diferenciam da discussão que sempre foi ponto de pauta na Educação Especial. Segundo Garcia e Michels (2018, p. 64), “O discurso político pós 2008 refuta a adaptação curricular, operando com a adequação dos recursos. Admite a ideia de flexibilização dos processos escolares. Afirma fortemente as ideias de diferenciação, mediante o processo de acessibilidade, aglutinados na formação de individualização do currículo".

Estamos no mesmo terreno da discussão sobre o acesso dos estudantes da Educação Especial à escola regular como um processo de exclusão interna, ou como afirmou Freitas (2002), por "trilhas diferenciadas". Nas propostas para a Educação Especial na pandemia, esse discurso de acesso diferenciado ficou mais evidente e é endossado pela produção acadêmica do campo específico, como demostram Barros e Uhmann, 
Atividades remotas, assim como outras, devem ser devidamente planejadas e os objetivos devem ser traçados, embora nem sempre dentro da lógica de conteúdos em que a escola se estabelece. Como conseguimos refletir durante essa pesquisa, mesmo diante das dificuldades abordadas, quando as adaptações curriculares são mantidas ou garantidas de alguma forma, o ensino remoto se torna menos penoso aos pais e alunos, além de se tornar possível suscitar outas vivências e experiências em meio à situação pandêmica que estamos enfrentando. (UHMANN, 2020, p. 11)

Para garantir a execução desse planejamento diferenciado, o qual foi destacado em grande parte dos textos acadêmicos selecionados, é necessário saber trabalhar com as tecnologias. A ideia geral transmitida é de que esse é o momento propício para desenvolver as potencialidades em torno do uso das tecnologias na educação, especialmente quando se trata da Educação Especial. Essa linha de raciocínio é trazida nos documentos analisados, mas o que mais nos chama a atenção é a utilização do termo treinamento. Os professores precisam ser treinados para se adequarem a essa "nova era". Seguindo as orientações da UNESCO, o Instituto Rodrigo Mendes ratifica que é necessário promover “[...] treinamento para professores e pais para o uso de ferramentas digitais" (INSTITUTO RODRIGO MENDES, 2020, p. 25). Ainda segundo o CNE "É preciso focar na "capacitação de professores para o uso de métodos inovadores e tecnologias de apoio são também ações indispensáveis do replanejamento curricular no contexto pós pandemia" (BRASIL, 2020b, p. 20).

O foco central, parece-nos, está pautado na técnica, nos materiais adaptados, hoje muito incentivados pelo uso das tecnologias digitais, como apontam Canal e Rozek:

O manuseio das ferramentas tecnológicas pelo professor do AEE de forma segura é algo imprescindível neste momento, pois além de adaptar situações de aprendizagem conjuntamente com os professores dos alunos, precisam intervir à distância, atentos a uma previsibilidade de possíveis situações no curso do que é proposto. (CANAL; ROZEK, 2021, p. 2681)

O trabalho do professor de Educação Especial pautado nas técnicas e materiais adaptados em detrimento de uma proposta de Educação Especial escolar, foi evidenciado 
na política da Educação Especial, na perspectiva da Educação Inclusiva de 2008 e proporcionou uma análise sobre a não ação docente desse professor específico. Entretanto, a ele são atribuídas as funções de técnico e gestor da inclusão nas escolas, ou seja, um professor multifuncional (VAZ, 2017). Nesse contexto de pandemia e de ensino remoto, as funções desse professor se amplificaram ainda mais. Conforme indicam Barcelos, Vaz e Garcia,

Com o início do isolamento social, decorrente da pandemia, as indicações para o professor do AEE extrapolam sua atuação multiprofissional e são atualizadas para o que estamos chamando de professor youtuber, o qual, além de trabalhar com as técnicas e materiais adaptados deve desenvolver habilidades midiáticas e ser submetido ao crivo da população em geral. (VAZ; GARCIA, 2020, p. 3)

As orientações apresentadas pela documentação e, muitas vezes, endossadas pela produção acadêmica, não apresentam diferenças das propostas já encaminhadas para a Educação Especial anteriormente à pandemia. Torres e Borges (2020), apontam a intensificação desses professores nesse momento. Segundo a pesquisa realizada pelas autoras, ao mesmo tempo que os professores tiveram que se readaptar às tecnologias, a participação dos estudantes diminuiu, demonstrando que a alternativa de ensino remoto para os estudantes da Educação Especial, por meio da enaltação das tecnologias, não garante a aprendizagem escolar.

O objetivo do ensino remoto para com os estudantes da Educação Especial não está pautando no ensino e aprendizagem dos conteúdos escolares. Essa perspectiva é endossada por pesquisas acadêmicas do campo específico, quando afirmam que

Talvez mais do que aprendizagens ditas acadêmicas, conteudistas, os alunos neste momento precisam aprender o valor da vida, a importância do autocuidado, a importância de poderem falar de seus sentimentos, medos, angústias. A aprendizagem formal pode ser recuperada, a hora agora é cuidar do ser humano. Acreditamos que a educação também aqui tem papel importante. Mostrar aos alunos e famílias a falta que faz estarmos todos juntos, podendo trocar e dialogar e que em algum momento estaremos fisicamente juntos de novo. (SILVA; BINS; ROZEK, 2020, p. 133) 
Tal reflexão, apesar de considerar o momento atípico que estamos vivendo, representa a hegemonia discursiva em torno do projeto de escola pública. A escola pública para o século XXI está cada vez mais direcionada para a sua "virada assistencial" (EVANGELISTA; LEHER, 2012) ou como aponta Algebaile (2009), como "posto de realização de ações sociais", em detrimento do acesso ao conhecimento científico. Essa característica, que também é alertada por Saviani (2013) na transposição da escola pública como "agência de assistência social", demonstra que o trabalho com os conteúdos escolares não é a atividade primordial da escola, e sim, possibilitar o desenvolvimento de habilidades socioemocionais, trazendo à tona um processo que podemos chamar de desescolarização na escola. Durante o ensino remoto e nos preparativos para o retorno presencial na pandemia do Coronavírus, esse projeto de escola não foi modificado, ao contrário, foi intensificado. Como afirma o Instituto Rodrigo Mendes (2020),

As escolas não são apenas ambientes de ensino e aprendizagem, mas também de alimentação, socialização e muitas vezes de suporte emocional para as crianças e adolescentes, além de serem essenciais para que os familiares dos estudantes com deficiências possam voltar aos seus trabalhos e assim garantir a sua renda da casa. (INSTITUTO RODRIGO MENDES, 2020, p. 30)

As avaliações feitas nos documentos destacados e em grande parte da produção acadêmica, para esse momento de ensino remoto, destacam a possibilidade de sairmos dessa experiência com pontos positivos. Para o Todos Pela Educação (2020), o momento atual pode ser um impulso para mudanças positivas e duradouras nos sistemas educacionais. Esses aspectos, centram-se justamente na compreensão da escola como espaço social e não de ensino e aprendizagem. "A escola é um dos equipamentos públicos com maior presença no dia a dia dos cidadãos e capilaridade no território, e pode ser continuamente aproveitada como grande aliada no atendimento intersetorial" (TPE, 2020, p. 22).

O discurso difundindo é de que a pandemia é uma oportunidade para repensar a escola conteudista e propor uma escola baseada em evidências. "A volta às aulas presenciais é uma oportunidade para reavaliarmos os princípios que estruturam o ensino, abrirmos mão de uma postura conteudista e perseguirmos objetivos de aprendizagem 
individualizados, contextualizados e inclusivos" (INSTITUTO RODRIGO MENDES, 2020, p. 46).

A negação do conteúdo, o ensino individualizado, o uso de tecnologias, a flexibilização curricular pautada no desenvolvimento individual são aspectos centrais dessa suposta "nova escola" que deve surgir após a pandemia, mas que já existe. A proposta de Educação Especial no ensino remoto, ao que tudo indica, não apresenta nenhuma inovação. Entretanto, o surgimento da pandemia proporcionou intensificar esse projeto de escola e de Educação Especial, destacando-se o uso de tecnologias para práticas inovadoras em prol do discurso de inclusão.

\section{A produção do discurso hegemônico para a Educação Especial: expressão do projeto de escola pública para o capital}

Mostrei até aqui alguns elementos que nos ajudam a compreender como está sendo produzido o consenso em torno das propostas de Educação Especial para o Brasil na atual conjuntura. A ideia geral está ancorada na defesa da inclusão dos sujeitos da Educação Especial na escola regular. Ao considerar a especificidade que estamos vivendo com o ensino remoto, o discurso hegemônico está pautado na necessidade de adequar a prática dos professores, indicando um currículo individualizado. Para isso, é imperativo um "novo" modelo de formação docente que abranja as demandas tecnológicas que todo o momento exige, ou melhor, treinamento docente. O ensino remoto, nesse sentido, contribui para evidenciar o projeto de formação de professores essencialmente prático, majoritariamente à distância e realizado em instituições privadas (EVANGELISTA et al., 2019).

Ao trazer os elementos apontados pela documentação analisada e as produções acadêmicas, pode-se perceber que encaminhados pelas Organizações Multilaterais, o CNE elabora orientações para o cumprimento do ano letivo, presencial ou não, e as organizações empresariais produzem documentos orientadores, utilizando-se de pesquisas de opinião ou de experiências de outros países, para auxiliar no consenso em torno da proposta educacional para o Brasil durante a pandemia da COVID-19. Concomitante a esses encaminhamentos, a produção acadêmica do campo específico da 
Educação Especial endossa todas as propostas, produzindo e demostrando o consenso em torno da Educação Especial na pandemia.

Destaca-se nesse consenso o protagonismo da família na relação com os resultados dos estudantes, a exaltação do uso das tecnologias para as práticas pedagógicas, a individualização do processo educativo, resultando na responsabilização individual dos sujeitos envolvidos e a necessidade de se investir em treinamento para os professores se adaptarem a esse "novo" modelo educacional.

O projeto privatista para a educação não está somente na formação de professores, mas também na gestão das escolas públicas. Freitas (2018) alerta para novas formas de privatização da educação pública, não mais de forma direta pela venda, mas na gestão pedagógica e na gestão do trabalho educativo, trazendo a concepção da escola como empresa.

É esta a visão social que também embasa as "soluções" propostas pela engenharia da reforma empresarial na educação. Pensando a escola como uma "empresa", as escolas de menor qualidade devem sucumbir às de maior qualidade, sendo fechadas; os estudantes de menor desempenho devem sucumbir aos de maior qualidade, sendo barrados em sucessivos testes; os professores de menor qualidade devem sucumbir aos de maior qualidade, sendo demitidos. Tal como na "empresa", os processos educativos têm que ser "padronizados" e submetidos a "controle". (FREITAS, 2018, p. 28)

É esse projeto de educação que está sendo executado e, intensificado, durante a pandemia. A ideia geral produzida pela maioria dos trabalhos acadêmicos selecionados neste estudo, indicam que esse projeto está a pleno vapor e, mais do que isso, é endossado por grande parte dos pesquisadores do campo específico da Educação Especial. Ao destacarem que é necessário rever as práticas docentes, utilizar as tecnologias, proporcionar um ensino individualizado, estão difundindo a concepção da escola que possibilita aos estudantes terem trilhas diferenciadas de aprendizagem - os que apresentam desempenhos diferenciados, terão encaminhamentos formativos diferentes. Ou ainda, a escola como espaço de socialização, formação de sujeitos adaptáveis ao mercado, sabendo trabalhar com tecnologias digitais, mas que não compreendem o mundo. 
O projeto de escola difundido por essa tríade - CNE, organizações empresariais e pesquisadores - não é a escola que visa proporcionar o desenvolvimento integral do sujeito com base na socialização do conhecimento científico produzido pela humanidade. Ainda que no discurso esteja presente essa ideia, ao que tudo indica, estamos retomando ou enfatizando uma versão da pedagogia do "aprender a aprender" (DUARTE, 2008). A concepção de uma educação voltada a discursos humanistas de direitos à diversidade, ao tempo de aprendizagem de cada indivíduo, ao interesse que cada um desperta em si, constitui uma dinâmica que descarta a importância do conhecimento científico. Um dos principais problemas é desconsiderar a função de formação da escola e a característica de ensino do professor, e delegar tudo isso ao próprio sujeito.

Trazer os elementos de adaptação do professor e de suas práticas para o ensino remoto com os estudantes da Educação Especial, sem considerar o projeto educacional que está sendo executado, é corroborar essa concepção de escola baseada nas práticas, que nega os conteúdos e que conduzem para o processo de desescolarização dos estudantes. Na Educação Especial, com a ênfase nas técnicas e materiais adaptados no $\mathrm{AEE}$, esse processo já estava em curso, entretanto, com o ensino remoto, a desescolarização dos estudantes da Educação Especial ficou ainda mais escancarada.

Cabe ressaltar que esta pesquisa foi desenvolvida com a pandemia ainda em curso; dessa forma, está em andamento e requer maiores aprofundamentos, especialmente sobre o efeito do consenso em torno do projeto de escola pública para com os estudantes da Educação Especial. O objetivo foi trazer alguns elementos para o debate, e, apontar a necessidade de pesquisas que desenvolvam análises, por exemplo, sobre as relações público-privadas, o trabalho docente e o currículo adaptado/flexibilizado como estratégias para a Educação Especial e que foram intensificadas com a pandemia da COVID-19.

\section{Referências}

ALGEBAILE, Eveline. Escola pública e pobreza no Brasil: a ampliação para menos. Rio de Janeiro: Lamparina, Faperj, 2009.

BARROS, Ludmila da Cruz; UHMANN, Silvana Matos. As (im)possibilidades do ensino remoto para aulo com o transtorno do espectro autista. In: SEMINÁRIO NACIONAL DE 
EDUCAÇÃO ESPECIAL, 6., SEMINÁRIO CAPIXABA DE EDUCAÇÃO INCLUSIVA, 17., Vitória.

Anais [...]. Vitória, ES: UFES, 2020. Disponível em: https://periodicos.ufes.br/snee. Acesso em: 10 abr. 2021.

BARCELOS, Liliam Guimarães de; VAZ, Kamille; GARCIA, Rosalba Maria Cardoso. Multifuncional e Youtuber: determinações do capital para o professor de educação especial. In: SEMINÁRIO NACIONAL DE EDUCAÇÃO ESPECIAL, 6.; SEMINÁRIO CAPIXABA DE EDUCAÇÃO INCLUSIVA, 17., Vitória. Anais [...]. Vitória, ES: UFES, 2020. Disponível em: https://periodicos.ufes.br/snee. Acesso em: 10 abr. 2021.

BEZERRA, Maria Aparecida Dantas; ARRUDA, Graziela Queiroz de; SILVA, Joelma Santana Reis da. Prática docente do Atendimento Educacional Especializado (AEE): em tempos remotos e distanciamento social. In: CONGRESSO NACIONAL DE EDUCAÇÃO, 7, Maceió. Anais [...]. Maceió, AL: CONEDU, 2020. Disponível em: http://editorarealize.com.br/artigo/visualizar/69330. Acesso em: 10 abr. 2021.

BRASIL. Ministério da Educação. Conselho Nacional de Educação. Conselho Pleno. Parecer n 05, de 28 de abril de 2020. Reorganização do Calendário Escolar e da possibilidade de cômputo de atividades não presenciais para fins de cumprimento da carga horária mínima anual, em razão da Pandemia da COVID-19. Diário Oficial da União, Brasília, DF, p. 1-24, 1 de jun. 2020a.

BRASIL. Ministério da Educação. Conselho Nacional de Educação. Conselho Pleno. Parecer $\mathrm{n}^{\circ}$ 11, de 7 de julho de 2020. Orientações Educacionais para a Realização de Aulas e Atividades Pedagógicas Presenciais e Não Presenciais no contexto da Pandemia. Diário Oficial da União, Brasília, DF, p. 1-29, 3 de ago. 2020b.

CANAL, Sandra; ROZEK, Marlene. Tempos de pandemia: reflexões sobre a escola, os sujeitos e a suas diferentes necessidades. Brazilian Journal of Development, Curitiba, PR, v. 7, n. 1, p. 2674-2683, jan. 2021.

\section{CONHECIMENTO SOCIAL. Retratos da educação no contexto da pandemia do}

coronavírus: perspectivas em diálogo. [S.I.], 2020. Disponível em:

http://movinovacaonaeducacao.org.br/wp-content/uploads/2020/12/Pesquisa-Retratos-daeducacao-no-contexto-da-pandemia-de-coronavirus.pdf. Acesso em: 06 abr. 2021.

DUARTE, Newton. Sociedade do conhecimento ou sociedade das ilusões?: quatro ensaios crítico-dialéticos em filosofia da educação. Campinas, SP: Autores Associados, 2008.

EVANGELISTA, Olinda; LEHER, Roberto. Todos pela educação e o episódio Costin no MEC: a pedagogia do capital em ação na política educacional brasileira. Trabalho Necessário, Rio de Janeiro, ano 10, n. 15, p. 1-29, 2012.

EVANGELISTA, Olinda; SHIROMA, Eneida. O caráter histórico da pesquisa em educação. Revista de Estudos Teóricos y Epistemológicos en Politica Educativa, Ponta Grossa, v. 4, p. 1-14, 2019. 
EVANGELISTA, Olinda et al. Desventuras dos professores na formação para o capital. Campinas, SP: Mercado das Letras, 2019.

FREITAS, Luiz Carlos de. A internalização da exclusão. Educação \& Sociedade, Campinas, SP, v. 23, n. 80, p. 301-327, set. 2002.

FREITAS, Luiz Carlos de. A reforma empresarial da educação: nova direita, velhas ideias. São Paulo: Expressão Popular, 2018.

FUNDAÇÃO CARLOS CHAGAS. Pesquisa: inclusão escolar em tempos de pandemia. [S.I.], 2020. Disponível em: https://www.fcc.org.br/inclusao-escolar-em-tempos-depandemia/\#: :text=A\%2opesquisa\%20\%E2\%80\%9CInclus\%C3\%A30\%20escolar\%20em,objetivo \%20de\%20identificar\%200s\%20desafios. Acesso em: 05 abr. 2021.

GOMES, Robéria Vieira Barreto et al. O trabalho docente no Atendimento Educacional Especializado: desafios e possibilidades em tempos de distanciamento social. Revista Educação em Debate, Fortaleza, ano 43, n. 84, p. 135-151, jan./abr. 2021.

GRAMSCI, Antônio. Cadernos do cárcere: volume 2. Rio de Janeiro: Civilização Brasileira, 2000.

INSTITUTO RODRIGO MENDES. Protocolos sobre Educação Inclusiva durante a Pandemia da COVID-19: um sobrevoo por 23 países e organismos internacionais. [S.I.], 2020. Disponível em: https://institutorodrigomendes.org.br/wpcontent/uploads/2020/07/protocolos-educacao-inclusiva-durante-pandemia.pdf. Acesso em: 05 abr. 2021.

MAGALHÃES, Tamara França de Almeida. A escolarização do estudante com deficiência em tempos de pandemia da COVID-19: tecendo algumas possibilidades. Revista Interinstitucional Artes de Educar, Rio de Janeiro, v. 6, número especial, p. 205-221, jun./out. 2020.

MARCOLLA, Valdinei. et al. Alunos com Necessidades Educacionais Específicas em tempos de COVID-19: da interrupção das aulas presenciais à implementação de atividades de ensino remotas. Revista Práxis, Volta Redonda, v.12, n. 1, p. 137-147, dez. 2020.

MARTINS, André Souza; PINA, Leonardo Docena. Classe social, Estado e hegemonia: a relação público-privada na educação. In: MOTTA, Vânia Cardoso da; PEREIRA, Larissa Dahmer (orgs.). Educação e Serviço Social: subsídios para uma análise crítica. Rio de Janeiro: Lumen Juris, 2017. p. 115-133.

MICHELS, Maria Helena; SHIROMA, Eneida Oto; EVANGELISTA, Olinda. Quatro teses sobre política de formação de professores. In: GENTIL, H. S.; MICHELS, M. H. (orgs.). Práticas Pedagógicas: política, currículo e espaço escolar. Araraquara, SP: Junqueira \& Marin; Brasília, DF: CAPES, 2011. p. 21-40. 
MICHELS, Maria Helena; GARCIA, Rosalba Maria Cardoso. Políticas de Educação Especial e currículo: disputas sobre natureza, perspectiva e enfoque. Revista Teias, Rio de Janeiro, v. 19, n. 55, p. 54-70, out./dez. 2018.

SILVA, Karla Fernanda Wunder da; BINS, Katiuscha Lara Genro; ROZEK, Marlene. A educação especial e a COVID-19: aprendizagens em tempos de isolamento social. Revista Interfaces Científicas, Aracaju, v. 10, n. 1, p. 124-136, número temático, 2020.

SOUZA, Artur Gomes de; EVANGELISTA, Olinda. Pandemia! janela de oportunidade para o Capital Educador. Contrapoder, [S. I.], 15 abr. 2020. Disponível em:

https://contrapoder.net/colunas/pandemia-janela-de-oportunidade-para-o-capitaleducador/. Acesso em: 30 mar. 2021.

SHIROMA, Eneida Oto. Ações em rede na educação: contribuições dos estudos do trabalho para a análise de redes sociais. In: ARAÚJO, M. de L.; RODRIGUES, D. S. (orgs.). A pesquisa em trabalho, educação e políticas educacionais. Campinas: Editora Alínea, 2012.

SAVIANI, Dermeval. Pedagogia histórico-crítica: primeiras aproximações. 11. ed. Campinas, SP: Autores Associados, 2013.

TODOS PELA EDUCAÇÃO. Nota técnica: o retorno às aulas presenciais no contexto da pandemia da COVID-19. [S.I.], 2020. Disponível em:

https://todospelaeducacao.org.br/wordpress/wp-

content/uploads/securepdfs/2021/01/433.pdf. Acesso em: 03 abr. 2021.

TORRES, Josiane Pereira; BORGES, Adriana Araújo Pereira. Educação Especial e a COVID19: o exercício da docência via atividades remotas. Revista Retratos da Escola, Brasília, v. 14, n. 30, p. 824-841, set./dez. 2021.

UNESCO. COVID-19: resposta educacional: nota informativa. [S.I.], 2020. Disponível em: https://observatoriodeeducacao.institutounibanco.org.br/api/assets/8cddce22-18e2-428bb6ac-9ecdb784494a/. Acesso em: 03 abr. 2021.

VAZ, Kamille. O projeto de professor para a educação especial: demandas do capital para a escola pública no século XXI. 2017. Tese (Doutorado em Educação) Universidade Federal de Santa Catarina, Centro de Ciências de Educação, Programa de Pós-Graduação em Educação, Florianópolis, 2017.

Recebido em: 17/04/2021 Aprovado em: 30/05/2021

Universidade do Estado de Santa Catarina - UDESC Programa de Pós-Graduação em Educação - PPGE Revista Linhas

Volume 22 - Número 49 - Ano 2021 revistalinhas@gmail.com 